\title{
Calidad nutricional, dinámica fermentativa y producción de metano de arreglos silvopastoriles ${ }^{1}$
}

\section{Nutritional quality, degradability and methane production in silvopastoral arrangements}

\author{
Liliana Mahecha-Ledesma², Joaquín Angulo-Arizala², Wilson Andrés Barragán-Hernández ${ }^{3}$
}

\begin{abstract}
Resumen
El objetivo de este trabajo fue evaluar la calidad bromatológica, la degradación de la materia seca y el potencial mitigador de metano del forraje proveniente de diferentes arreglos silvopastoriles bajo tres niveles de sombra $(0,30 \mathrm{y} 60 \%)$. Este estudio se llevó a cabo entre octubre de 2012 y setiembre de 2013 en la hacienda La Candelaria de la Universidad de Antioquia, Colombia. Para los arreglos se utilizaron gramíneas de género Brachiaria (Brachiaria brizantha cv toledo, Brachiaria decumbens y Brachiaria hibrido cv mulato II) solas o asociadas con Tithonia diversifolia y Cratilya argentea en arreglo silvopastoril. La evaluación se realizó en el forraje de cuarenta días, se determinó la composición química, contenido de ácidos grasos poliinsaturados, degradación de la materia seca y producción de metano in vitro. El arreglo utilizado (gramínea sola o asociada a arbustiva) afectó significativamente la concentración de proteína y ácido linoleico $(\mathrm{p}<0,05)$. No se presentó efecto del arreglo, el nivel de sombra ni de la interacción arreglo x sombra sobre la degradación de la materia seca a las $48 \mathrm{~h}(\mathrm{p}>0,05)$. Sin embargo, pruebas planeadas indicaron que al asociar Brachiaria brizantha $\mathrm{cv}$ toledo con las arbustivas, se mejoró la degradación de la materia seca (MS) a las 48 h y se observó que la interacción arreglo x sombra afectó la dinámica de esta. Los factores evaluados (arreglo y sombra) no influyeron en la emisión de metano in vitro.
\end{abstract}

Palabras clave: sistemas silvopastoriles, gramíneas forrajeras, Cratylia argentea, ácidos grasos poliinsaturados, Tithonia diversifolia.

\begin{abstract}
The aim of this work was evaluate the bromatological quality, the degradability of dry matter and the mitigation potential of the forage from the different silvopastoral arrangements in three shade levels $(0,30 \mathrm{y} 60 \%)$. This study was carried out between October 2012 and September 2013, in the La Candelaria farm from the Antioquia University, Colombia. The arrangements contained within Brachiaria grasses (Brachiaria brizantha cv toledo, Brachiaria decumbens and Brachiaria hibrido cv mulato II) alone or associated with Tithonia diversifolia and Cratilya argentea in silvopastoral arrangements. Evaluation was made in forage of forty days, the chemical composition, content
\end{abstract}

\footnotetext{
Recibido: 7 de enero, 2016. Aceptado: 28 de junio, 2016. Trabajo desarrollado en el marco del proyecto de investigación "Evaluación de las emisiones de metano entérico de gramíneas y especies arbustivas sometidas a niveles crecientes de sombra y su relación con la composición bioquímica, nutricional y estructural, como indicador de la capacidad de los sistemas silvopastoriles para mitigar el efecto del calentamiento global" financiado por Centro de Investigación de Ciencias Agrarias de la Universidad de Antioquia, Colombia.

2 Universidad de Antioquia, Facultad de Ciencias Agrarias. Grupo de Investigación en Ciencias Agrarias (GRICA) - Sistemas Sostenibles de Producción Animal. Ciudadela de Robledo, Carrera 75 N 65•87, Medellín (Ant), Colombia. Liliana.mahecha@udea.edu.co (autora para correspondencia), Joaquin.angulo@udea.edu.co

3 Corporación Colombiana de Investigación Agropecuaria (CORPOICA), Centro de Investigación Turipaná. Km 13 vía Montería-Cereté (Córd.), Colombia.wbarraganh@corpoica.org.co
} 
of polyunsaturated fatty acids, degradation of dry matter and in vitro methane production were determined. The arrangement used (grass alone or associated with shrubs affected significantly the concentration of protein and linoleic acid $(\mathrm{p}<0.05)$. Not effect was observed in the arrangement, level of shade and interaction arrangement $\mathrm{x}$ shade in the degradability of dry mater after $48 \mathrm{~h}(\mathrm{p}>0.05)$. However, pre-planned comparisons indicated that the association of Brachiaria brizantha cv toledo with shrubs improved the degradability of dry matter (MS) at $48 \mathrm{~h}$, and was observed that the interaction shade $\mathrm{x}$ arrangement affected the dynamic degradation of MS. The factors evaluated (arrangement and shade) did not affect the in vitro methane emission.

Keywords: silvopastoral systems, feed grasses, Cratylia argentea, polyunsatured fatty acids, Tithonia diversifolia .

\section{Introducción}

El cambio climático es uno de los peores desafíos que la humanidad deberá afrontar en el presente siglo. Amenaza el logro de los objetivos de desarrollo del milenio y puede acarrear un retroceso en los niveles de desarrollo humano en todos los países, especialmente en aquellos en vía de desarrollo y en las comunidades más pobres y vulnerables (Cote et al., 2010).

Los gases de efecto invernadero (GEI) son una de las causas del cambio climático, dentro de los cuales el metano $\left(\mathrm{CH}_{4}\right)$ representa una marcada importancia por poseer veintiún veces más potencial de calentamiento global (GWP) que el dióxido de carbono (Pinares-Patiño, 2014).

Los rumiantes han sido uno de los principales ejes de desarrollo de la humanidad, contribuyendo con aporte de proteína de alto valor biológico a partir de residuos fibrosos y subproductos agrícolas e industriales. Sin embargo, el proceso fermentativo de los residuos fibrosos, genera GEI como subproducto, los cuales son expulsados hacia el ambiente (Carmona et al., 2005). Se estima que cerca del 18\% del total de emisiones de GEI son atribuidas a los bovinos, búfalos, ovejas, cabras, camellos, cerdos y aves (Steinfeld et al., 2006), con particular énfasis en los producidos por bovinos y ovejas, los cuales corresponden al 25 y $21 \%$, respectivamente, del total de emisiones antropogénicas a escala global en la agricultura (Lascano y Cárdenas, 2010).

Además de constituirse en un problema ambiental, la emisión de metano en los rumiantes representa una pérdida energética en la eficiencia alimenticia, la cual, en la mayoría de los casos, varía entre el 6 y el 7\% de la energía bruta ingerida (Pinares-Patiño, 2014). Estos antecedentes han motivado el esfuerzo de gobiernos y grupos de investigación en el desarrollo de estrategias eficientes para afrontar esta problemática, con mayor énfasis en las modificaciones dietarias (Grainger y Beauchemin, 2011).

Varios autores ilustran un amplio volumen de trabajos que han sido desarrollados como alternativas para mitigar las emisiones de metano entérico (Hristov et al., 2013). Los resultados de esta revisión apuntan a concluir que la mayoría de las alternativas de alto potencial para mitigar las emisiones de metano no son recomendadas por sus efectos colaterales en el animal y en el ambiente, y para el caso de las alternativas recomendadas, evidencian bajo potencial de mitigación y poca o nula evaluación de desempeño en largo término, entre estas últimas, se destacan el uso de lípidos en la dieta y los compuestos secundarios en plantas.

Los lípidos pueden reducir la emisión de metano disminuyendo la cantidad de materia orgánica fermentada en el rumen, la actividad de las bacterias metanogénicas, el número de protozoos, y a través del uso de hidrógeno durante el proceso de biohidrogenación (Johnson y Johnson, 1995). Estudios realizados han demostrado un efecto en la disminución de la producción de metano ruminal con el uso de los ácidos grasos C18: oleico, linoleico y linolénico (Jalc et al., 2007). Se considera que los ácidos grasos de la dieta, principalmente los poliinsaturados, constituyen una de las alternativas dietarias más prometedoras para deprimir la metanogénesis (Martin et al., 2006). Por consiguiente, es de gran importancia identificar gramíneas y arbustivas con concentraciones promisorias de ácidos grasos polinsaturados, y definir su vinculación con las emisiones de metano entérico. Al respecto, se 
han reportado cambios significativos en el contenido de ácidos grasos poliinsaturados en diferentes especies de gramíneas y leguminosas, de acuerdo con atributos agronómicos como la edad del rebrote y la fertilización nitrogenada (León et al., 2011). No obstante, no existen trabajos que reporten el efecto de los niveles de sombra o de la asociación pasto-arbustivas sobre el contenido de ácidos grasos poliinsaturados en gramíneas y arbustivas.

Los compuestos secundarios en las plantas, tales como taninos y saponinas, también han demostrado ser una alternativa eficiente en la reducción de metano entérico (Kamra et al., 2006; Mirzaei-Aghsaghali y Maheri-Sis, 2011). Los mecanismos de acción que median la disminución de metano están influenciados por la interacción de las saponinas con el colesterol presente en las membranas de las células eucariotas, mas no en las de células procariotas, por consiguiente, afectan el desarrollo de los protozoarios en el rumen, sin inhibir el crecimiento bacteriano (Wina et al., 2005). En este sentido, el uso de especies arbustivas y leguminosas en la dieta de los rumiantes, por efectos de metabolitos secundarios y de mayor valor nutricional, constituyen una herramienta potencial para disminuir las emisiones de metano (Mayorga et al., 2014).

Bajo condiciones agroecológicas de la subregión del Bajo Cauca Antioqueño en la cual predominan sabanas ácidas y colinadas (Pulido et al., 2002), se reduce el abanico de opciones de arbustivas para conformar sistemas silvopastoriles. Bajo estas condiciones, se ha reportado que el desempeño agronómico de las arbustivas Tithonia diversifolia y Cratylia argentea, en compañía de gramíneas del género Brachiaria, resultan en un asocio promisorio para el establecimiento de arreglos silvopastoriles (Mahecha et al., 2015). Sin embargo, pese a que se han reportado que estos arbustos pueden ser utilizados en alimentación de rumiantes (Hess et al., 2004; Galindo et al., 2011), se hace necesario evaluar la dinámica en la degradación de forrajes de las combinaciones gramínea-arbustiva, y su consecuente emisión de metano.

Son importantes las estrategias para determinar arreglos potenciales para utilizar en sistemas silvopastoriles bajo condiciones del Bajo Cauca Antioqueño; por ello, se planteó como objetivo de este trabajo evaluar la calidad bromatológica, degradabilidad de la materia seca y potencial mitigador de metano de diferentes arreglos silvopastoriles bajo tres niveles de sombra.

\section{Materiales y métodos}

\section{Área de estudio}

El ensayo se llevó a cabo entre octubre de 2012 y septiembre de 2013 en la hacienda La Candelaria de la Universidad de Antioquia, ubicada en el municipio de Caucasia (Antioquia) a 7 $58^{\prime} 46^{\prime \prime}$ de latitud norte y $75^{\circ} 11^{\prime} 40^{\prime \prime}$ de longitud oeste. Esta zona corresponde a la clasificación de bosque húmedo tropical (bh-T), con las siguientes características agroecológicas: altitud de $50 \mathrm{msnm}$, temperatura promedio de $28{ }^{\circ} \mathrm{C}, 2382 \mathrm{~mm}$ de precipitación anual promedio $2382 \mathrm{~mm}$ y una humedad relativa entre 75-80\% (Mahecha et al., 2004).

\section{Diseño experimental}

En el desarrollo de este trabajo se utilizaron las especies Brachiaria brizantha cv toledo, Brachiaria decumbens y Brachiaria hibrido cv mulato II, por ser especies reportadas como tolerantes a condiciones de sombra, acidez y con potencial productivo para ser utilizadas en sistemas silvopastoriles. Las especies arbustivas utilizadas fueron Cratylia argentea y Tithonia diversifolia.

En un área de $650 \mathrm{~m}^{2}$ con una pendiente menor al 5\%, se establecieron dos bloques para controlar el efecto de fertilidad del suelo (Cuadro 1). Se evaluó la respuesta de la gramínea sola y acompañada de C.argentea y/o de $T$. diversifolia, lo que se denominó efecto del arreglo utilizado (Cuadro 2). 
Cuadro 1. Análisis del suelo en el área de estudio. Hacienda La Candelaria, Universidad de Antioquia, Caucasia, Antioquia, Colombia. 2012.

Table 1. Soil analysis of the study area. The Candelaria farm, University of Antioquia, Caucasia, Antioquia, Colombia. 2012.

\begin{tabular}{ccccccccc}
\hline Bloque & $\mathbf{p H}$ & $\mathbf{M O}$ & $\mathbf{A l}$ & $\mathbf{C a}$ & $\mathbf{M g}$ & $\mathbf{K}$ & $\mathbf{C I C E}$ & $\mathbf{P}$ \\
\cline { 3 - 9 } & & $\mathbf{\%}$ & & & $\mathbf{C m o l} / \mathbf{k g}$ & & & $\mathbf{M g} / \mathbf{k g}$ \\
\hline I & 4,9 & 2,5 & 5,1 & 7,07 & 1,9 & 0,57 & 14,6 & 1 \\
II & 5,0 & 2,8 & 1,9 & 11,7 & 1,3 & 0,26 & 15,2 & 1 \\
\hline
\end{tabular}

pH: potencial de hidrógenos, MO: materia orgánica, Al: aluminio, Ca: calcio, Mg: magnesio, $\mathrm{K}$ : potasio, CICE: capacidad de intercambio catiónico efectiva, P: fósforo / pH: hydrogen potential, MO: organic matter, $\mathrm{Al}$ : aluminum, $\mathrm{Ca}$ : calcium, Mg: magnesium, $\mathrm{K}$ : potasium, CICE: effective cation exchange capacity, P: phosphorus.

Cuadro 2. Arreglos de gramíneas solas o asociadas a arbustivas en arreglo silvopastoril que se emplearon para determinar su uso potencial en el Bajo Cauca Antioqueño. Hacienda La Candelaria, Universidad de Antioquia, Caucasia, Antioquia, Colombia. 2012.

Table 2. Grasses arrangements alone or associates to strumbs in silvopastoral arrangements that were employed in order to determine their potential use in Bajo Cauca Antioquia. Candelaria farm, University of Antioquia, Caucasia, Antioquia, Colombia. 2012.

\begin{tabular}{llllll}
\hline $\mathbf{N}$ & Arreglo & N & Arreglo & N & Arreglo \\
\hline 1 & Brachiaria brizantha cv Toledo & 5 & Brachiaria decumbens & 9 & Brachiaria hibrido cv MulatoII \\
2 & B. brizantha cv Toledo + Cratylia argentea & 6 & B. decumbens + C. argentea & 10 & B. hibrido cv MulatoII + C. argentea \\
3 & $\begin{array}{l}\text { B. brizantha cv Toledo + Tithonia } \\
\text { diversifolia }\end{array}$ & 7 & B.decumbens + T. diversifolia & 11 & $\begin{array}{l}\text { B. hibrido cv MulatoII }+T \text {. } \\
\text { diversifolia }\end{array}$ \\
& B. cv Toledo + C. argentea + T. diversifolia & 8 & $\begin{array}{l}\text { B. decumbens }+ \text { C. argentea }+ \\
\text { T. diversifolia }\end{array}$ & $\begin{array}{l}\text { B. hibrido cv MulatoII }+ \text { C. argentea } \\
+ \text { T. diversifolia }\end{array}$ \\
\hline
\end{tabular}

Las gramíneas solas o asociadas se aleatorizaron en 72 parcelas con dimensiones de $4 \mathrm{~m}^{2}$. En todas las parcelas los surcos estaban separados a $25 \mathrm{~cm}$. Para el caso de gramíneas, la siembra se realizó a chorrillo con semilla sexual, se consideraron diez plantas por metro lineal, y para el caso de las arbustivas se realizó a $25 \mathrm{~cm}$ entre planta, con semilla sexual, previa germinación en fase de vivero.

En cada uno de los bloques se arregló de manera aleatoria un diseño de parcelas divididas, tomando como parcela principal el nivel de sombra, el cual fue 0,30 y 60\%; y en la subparcela, el arreglo utilizado (gramíneas solas o asociadas con arbustivas en arreglo silvopastoril). La sombra fue simulada con tela negra de polipropileno. En total se obtuvieron 72 unidades experimentales (2 bloques x 3 niveles de sombra x 12 arreglos).

\section{Cosecha de la muestra}

A los 120 días después del establecimiento se realizó un corte de uniformidad a $25 \mathrm{~cm}$ del suelo, y cuarenta días después de la uniformización, se realizó el corte de evaluación en las 72 parcelas del experimento, en el cual se cosechó una muestra de $1 \mathrm{~kg}$ en forraje fresco. Al cosechar el forraje total de la parcela, la composición por metro cuadrado estuvo conformada por $100 \%$ gramíneas en los arreglos de solo gramínea; $98 \%$ gramínea y 2\% arbustiva en los arreglos en donde se combinó gramínea con una sola arbustiva; y 97\% gramínea, 1,5\% C. argentea y 1,5\% T. diversifolia, en los arreglos en los que la gramínea se encontraba asociada con dos arbustivas. Esas proporciones 
se conservaron en la toma de la muestra para análisis de laboratorio. La muestra se secó a $65^{\circ} \mathrm{C}$ por 72 horas, luego se molió en malla de $1 \mathrm{~mm}$, utilizando un molino estacionario Thomas-Wiley modelo 4.

\section{Composición química}

La composición química de la muestra tomada se derminó mediante las técnicas analíticas convencionales de la AOAC (1999) (cenizas método ID 942.05, proteína bruta método ID 984.13), y los métodos descritos por Van Soest et al. (1991) para fibra detergente neutro y fibra detergente ácido.

Para la determinación de las concentraciones de ácido linoleico y linolénico en los arreglos silvopastoriles evaluados, se siguió el protocolo estandarizado por el Laboratorio del Grupo Interdisciplinario de Estudios Moleculares (GIEM) de la Universidad de Antioquia. Este protocolo se corrió en dos fases, en la primera se tomaron entre 0,15 a $0,20 \mathrm{~g}$ de muestra, a las cuales se les adicionó $4 \mathrm{ml}$ de $\mathrm{NaOH} 0,5 \mathrm{~N}$ en metanol, para posteriormente ser calentado en "baño de maría" a $90{ }^{\circ} \mathrm{C}$ por espacio de $7 \mathrm{~min}$; terminado este tiempo se adicionó $5 \mathrm{ml}$ de BF3 al $12 \%$ en metanol con reposo de $2 \mathrm{~min}$; posteriormente, se adicionaron $4 \mathrm{ml} \mathrm{de} \mathrm{N}$-Heptano con reposo de $1 \mathrm{~min}$. Para finalizar la fase de extracción, se adicionó $100 \mathrm{ml}$ de solución saturada de $\mathrm{NaCl}$ para garantizar la separación de la fase orgánica en el tubo, la cual se retiró con pipeta Pasteur para almacenarla en un tubo de ensayo, al que se le adicionó sulfato de sodio anhidro para retirar la humedad.

En la segunda fase se realizó la cuantificación mediante cromatografía de gases, se empleó un equipo Agilent 6890, con una columna DB-23 capilar de $50 \mathrm{~m}$, diámetro interno de $0,25 \mathrm{~mm}$ y espesor de película de $1,4 \mu \mathrm{m}$. La corrida se realizó utilizando el hidrógeno como gas portador a una temperatura del detector de $280{ }^{\circ} \mathrm{C}$ y del inyector de $250{ }^{\circ} \mathrm{C}$.

\section{Cinética de la fermentación ruminal in vitro}

La cinética de fermentación se determinó mediante la técnica de producción de gas in vitro (Menke y Steingass, 1988; Theodorou et al., 1994), modificada por Posada et al. (2006). La incubación se llevó a cabo en frascos de vidrio oscuros con capacidad de $100 \mathrm{ml}$ cada uno. En cada frasco se adicionó entre 0,45 y 0,47 g de cada muestra tomada, seca y molida a $1 \mathrm{~mm}$ (gramíneas solas o mezcladas con una o las dos forrajeras en las proporciones mencionadas). La solución buffer (saliva artificial) se preparó de acuerdo con las recomendaciones de McDougall (1948), se utilizó una relación buffer/inóculo ruminal de 9/1 (45/5 ml/ml). Los frascos con la saliva artificial permanecieron en estufa de ventilación forzada a $39^{\circ} \mathrm{C}$ por cuatro horas, antes de la inoculación con fluido ruminal.

El líquido ruminal se obtuvo de tres novillos que consumían pastos del trópico bajo colombiano. La colecta se hizo inmediatamente después del sacrificio, se filtró en paños de algodón y se almacenó en termos calentados previamente con agua a $40{ }^{\circ} \mathrm{C}$. En el laboratorio, el líquido ruminal de cada animal se filtró nuevamente y fue transferido a tres erlenmeyer (uno por cada animal), los cuales se saturaron con $\mathrm{CO}_{2}$ y se mantuvieron en estufa a $39^{\circ} \mathrm{C}$, durante el tiempo que demoró la inoculación.

Los frascos de incubación se inocularon con $10 \mathrm{ml}$ de líquido ruminal y posteriormente, se sellaron con tapas de caucho. Para su ubicación en la estufa de ventilación forzada a $39{ }^{\circ} \mathrm{C}$, se dispusieron en cajas de icopor que ayudaron a conservar la temperatura.

En total fueron incubados 450 frascos, que estaban conformados de la siguiente manera: 432 con sustrato e inóculo (72 muestras de forraje $\mathrm{x} 3 \mathrm{~h}$ de evaluación $\mathrm{x} 2$ frascos por muestra) y dieciocho frascos correspondientes a blancos ( 3 h de evaluación $\mathrm{x} 2$ frascos por muestra x 3 inóculos ruminales).

La concentración de metano de los arreglos silvopastoriles evaluados, se determinó mediante el gas acumulado hasta las $48 \mathrm{~h}$. La colecta de gas se realizó utilizando una válvula de tres salidas. La primera salida se conectó a una aguja $(0,6 \mathrm{~mm})$, la segunda al transductor de presión y la tercera a una jeringa plástica que sirvió para la extracción del volumen de gas. La aguja acoplada a la válvula se insertó a través de la tapa de caucho para la medición de la 
presión y posteriormente, los gases acumulados en la parte superior del frasco se retiraron con el uso de la jeringa, hasta el punto en que la presión registrada en el transductor alcanzó a ser cero. El gas colectado en la jeringa se trasladó y se almacenó en bolsas plásticas herméticamente cerradas, a partir de las cuales se tomaron muestras de $100 \mu \mathrm{l}$, que se inyectaron en un cromatógrafo de gases adaptado con un detector de ionización de llama (FID). Las condiciones cromatográficas se adaptaron de Apráez et al. (2012) y correspondieron a una columna apolar de 30 $\mathrm{m}, 0,32 \mathrm{~mm}$ y $0,25 \mu \mathrm{m}$. Temperatura del puerto de inyección $200{ }^{\circ} \mathrm{C}$, modo de inyección split $50: 1$, temperatura del detector $250{ }^{\circ} \mathrm{C}$, temperatura del horno $30{ }^{\circ} \mathrm{C}(5 \mathrm{~min})$ hasta completar $200{ }^{\circ} \mathrm{C}\left(30^{\circ} \mathrm{C} / \mathrm{min}\right)$ y helio como gas de arrastre $(1,0 \mathrm{ml} / \mathrm{min})$. Los datos de concentración de metano se procesaron de acuerdo con la descripción dada por Lopez y Newbold (2007). La producción de este ( $\mathrm{ml}$ ) se obtuvo del producto entre el volumen total de gas (ml) y la concentración relativa de metano. La tasa de producción de metano $(\mathrm{ml} / \mathrm{g} \mathrm{MSi})$ se obtuvo dividiendo la producción de metano ( $\mathrm{ml} / \mathrm{g} \mathrm{MSi}$ ) entre los gramos de materia seca incubada.

La degradabilidad de la materia seca del forraje se midió a las 12, 24 y 48 h. Las diferencias estadísticas fueron analizadas solamente a las $48 \mathrm{~h}$. Adicionalmente, los resultados obtenidos de la degradabilidad de la materia seca a las 12, 24 y 48 h, se modelaron de acuerdo con lo descrito por Orskov y McDonald (1979), mediante la siguiente ecuación:

$$
\mathrm{P}=\mathrm{a}+\mathrm{b}^{*}\left(1-\exp ^{-\mathrm{c} * t}\right)
$$

Donde:

$\mathrm{P}=$ degradabilidad potencial.

t= tiempo de incubación $(12,24$ y 48 h).

$\mathrm{a}=$ Intercepto con el eje $\mathrm{Y}$ en el tiempo cero.

$\mathrm{b}=$ diferencia entre el intercepto a y la asíntota.

$\mathrm{c}=$ tasa constante de la función $\mathrm{b}$.

$1-(a+b)=$ representa la fracción no degradable.

Todos los procedimientos analíticos se llevaron a cabo en el Laboratorio de Investigaciones en Nutrición y Alimentación Animal (NUTRILAB) de la Universidad de Antioquia.

\section{Análisis estadístico}

El contenido de ácidos grasos, la degradabilidad de la MS a las 48 h y la producción de metano se analizaron empleando un diseño de parcelas divididas, se consideró en el modelo estadístico el efecto del i-ésimo bloque (B1 y B2), el efecto de la j-ésima parcela principal (nivel de sombra 0, 30 y 60\%), el error de la parcela principal (eij $\mathrm{N}(0,1) \sigma^{2}$ constante), el efecto de la k-ésimo arreglo (gramínea sola o asociada con una o dos arbustivas en arreglo silvopastoril), y por último, la interacción de los factores sombra y arreglo. Los datos se analizaron mediante el procedimiento Mixed del paquete estadístico SAS, como efectos fijos los niveles de sombra y arreglo, y como efectos aleatorios el efecto del bloque y los errores asociados al diseño experimental. En caso de rechazo de la hipótesis nula, se consideró el test Tukey con un alfa al 0,05. Se consideró como tendencia una probabilidad entre 0,05 y 0,1 . Los datos correspondientes a la degradación de la materia seca se estimaron empleando un modelo no lineal de acuerdo con lo descrito por Orskov y McDonald (1979), a través del procedimiento NLIN y el algoritmo Marquardt.

Se realizaron comparaciones planeadas para la variable degradación de materia seca a las 48 h, según se indica en el Cuadro 3. 
Cuadro 3. Comparaciones planeadas entre los diferentes arreglos utilizados (gramíneas solas o asociadas a arbustivas en arreglo silvopastoril, para determinar su uso potencial en el Bajo Cauca Antioqueño. Hacienda La Candelaria, Universidad de Antioquia Caucasia, Antioquia, Colombia. 2013.

Table 3. Planned comparisons between the different arrangements used (grassed alone or associated to shrubs in silvopastoral arrangement), in order to determine their potential use in Bajo Cauca, Antioquia. The Candelaria farm, University of Antioquia, Caucasia, Antioquia, Colombia. 2013.

\begin{tabular}{|c|c|c|}
\hline Descripción & Contraste & Abreviatura \\
\hline \multirow{3}{*}{$\begin{array}{l}\text { Comparar las la respuesta de gramíneas } \\
\text { en monocultivo }\end{array}$} & B. decumbens vs B. hibrido cv mulato II & $\mathrm{BD}$ vs BM \\
\hline & B. decumbens vs B. brizantha cv toledo & $\mathrm{BD}$ vs $\mathrm{BT}$ \\
\hline & B. hibrido cv mulato II vs $B$. brizantha $\mathrm{cv}$ toledo & $\mathrm{BM}$ vs BT \\
\hline \multirow{3}{*}{$\begin{array}{l}\text { Gramínea } B . \text { decumbens en monocultivo } \\
\text { vs } B \text {. decumbens en arreglo SSP }\end{array}$} & B. decumbens vs SSP con C. argentea & $\mathrm{BD}$ vs $\mathrm{BD}+\mathrm{C}$ \\
\hline & B. decumbens vs SSP com C. argentea y T. diversifolia & $\mathrm{BD}$ vs $\mathrm{BD}+\mathrm{C}+\mathrm{T}$ \\
\hline & B. decumbens vs SSP com T. diversifolia & $\mathrm{BD}$ vs $\mathrm{BD}+\mathrm{T}$ \\
\hline \multirow{3}{*}{$\begin{array}{l}\text { Gramínea } B . \text { brizantha cv toledo en } \\
\text { monocultivo vs } B \text {. brizantha en arreglo } \\
\text { SSP }\end{array}$} & B. brizantha cv toledo vs SSP con $C$. argentea & $\mathrm{BT}$ vs $\mathrm{BT}+\mathrm{C}$ \\
\hline & B. brizantha cv toledo vs SSP com $C$. argentea y $T$. diversifolia & $\mathrm{BT}$ vs $\mathrm{BT}+\mathrm{C}+\mathrm{T}$ \\
\hline & B. brizantha cv toledo vs SSP com T. diversifolia & $\mathrm{BT}$ vs $\mathrm{BT}+\mathrm{T}$ \\
\hline \multirow{3}{*}{$\begin{array}{l}\text { Gramínea } B \text {. hibrido cv mulato II en } \\
\text { monocultivo vs } B \text {. hibrido } \mathrm{cv} \text { mulato II } \\
\text { en arreglo SSP }\end{array}$} & B. hibrido cv mulato II vs SSP con C. argentea & $\mathrm{BM}$ vs $\mathrm{BM}+\mathrm{C}$ \\
\hline & B. hibrido cv mulato II vs SSP com C. argentea y $T$. diversifolia & $\mathrm{BM}$ vs $\mathrm{BM}+\mathrm{C}+\mathrm{T}$ \\
\hline & B. hibrido cv mulato II vs SSP com $T$. diversifolia & $\mathrm{BM}$ vs $\mathrm{BM}+\mathrm{T}$ \\
\hline $\begin{array}{l}\text { Todas las gramíneas en monocultivo vs } \\
\text { todas las gramíneas en SSP solo con } C \text {. } \\
\text { argentea }\end{array}$ & $\begin{array}{l}B . \text { hibrido cv mulato II, } B \text {. decumbens y } B . \text { brizantha cv toledo } \\
\text { vs } B \text {. hibrido cv mulato II, } B \text {. decumbens y } B \text {. brizantha } \mathrm{cv} \\
\text { toledo en SSP con } C \text {. argentea }\end{array}$ & $\begin{array}{l}\text { BD BM BT vs } \\
\mathrm{BD}+\mathrm{C} \mathrm{BM}+\mathrm{C} \\
\mathrm{BT}+\mathrm{C}\end{array}$ \\
\hline $\begin{array}{l}\text { Todas las gramíneas en monocultivo } \\
\text { vs todas las gramíneas en SSP con } C \text {. } \\
\text { argentea y } T \text {. diversifolia }\end{array}$ & $\begin{array}{l}B . \text { hibrido cv mulato II, } B \text {. decumbens y } B \text {. brizantha cv toledo } \\
\text { vs } B \text {. hibrido cv mulato II, } B \text {. decumbens y } B \text {. brizantha } \mathrm{cv} \\
\text { toledo en SSP con } C \text {. argentea y } T \text {. diversifolia }\end{array}$ & $\begin{array}{l}\text { BD BM BT vs } \\
\mathrm{BD}+\mathrm{C}+\mathrm{T} \mathrm{BM}+\mathrm{C}+\mathrm{T} \\
\mathrm{BT}+\mathrm{C}+\mathrm{T}\end{array}$ \\
\hline $\begin{array}{l}\text { Todas las gramíneas en monocultivo vs } \\
\text { todas las gramíneas en SSP solo con } T \text {. } \\
\text { diversifolia }\end{array}$ & $\begin{array}{l}B . \text { hibrido cv mulato II, } B \text {. decumbens y } B \text {. brizantha cv toledo } \\
\text { vs } B \text {. hibrido cv mulato II, B. decumbens y } B \text {. brizantha } \mathrm{cv} \\
\text { toledo en SSP conT. diversifolia }\end{array}$ & $\begin{array}{l}\text { BD BM BT vs } \\
\mathrm{BD}+\mathrm{T} \mathrm{BM}+\mathrm{T} \\
\mathrm{BT}+\mathrm{T}\end{array}$ \\
\hline $\begin{array}{l}\text { Gramínea } B . \text { decumbens en monocultivo } \\
\text { vs todas las combinaciones de } B \text {. } \\
\text { decumbens en arreglo SSP }\end{array}$ & $\begin{array}{l}\text { B. decumbens vs } B . \text { decumbens con } C \text {. argentea, B. decumbens s } \\
\text { con } C \text {. argentea y } T \text {. diversifolia y } B . \text { decumbens con } \\
T . \text { diversifolia }\end{array}$ & $\begin{array}{l}\mathrm{BD} \text { vs } \mathrm{BD}+\mathrm{C} \\
\mathrm{BM}+\mathrm{C}+\mathrm{T} \mathrm{BD}+\mathrm{T}\end{array}$ \\
\hline $\begin{array}{l}\text { Gramínea } B \text {. hibrido cv mulato II en } \\
\text { monocultivo vs todas las combinaciones } \\
\text { de } B \text {. hibrido cv mulato II en SSP }\end{array}$ & $\begin{array}{l}B \text {. hibrido cv mulato II vs mulato II con } C \text {. argentea, mulato II } \\
\text { con } C \text {. argentea y } T \text {. diversifolia y mulato II con } T \text {. diversifolia }\end{array}$ & $\begin{array}{l}\mathrm{BM} \text { vs } \mathrm{BM}+\mathrm{C} \\
\mathrm{BM}+\mathrm{T}+\mathrm{C} \mathrm{BM}+\mathrm{T}\end{array}$ \\
\hline $\begin{array}{l}\text { Gramínea } B . \text { brizantha cv toledo en } \\
\text { monocultivo vs todas las combinaciones } \\
\text { de } B . \text { brizantha } \mathrm{cv} \\
\text { toledo en SSP }\end{array}$ & $\begin{array}{l}\text { B. brizantha cv toledo vs toledo con } C \text {. argentea, toledo con } C \text {. } \\
\text { argentea y } T \text {. diversifolia y toledo con } T \text {. diversifolia }\end{array}$ & $\begin{array}{l}\mathrm{BT} \text { vs } \mathrm{BT}+\mathrm{C} \\
\mathrm{BT}+\mathrm{C}+\mathrm{T} \mathrm{BT}+\mathrm{T}\end{array}$ \\
\hline
\end{tabular}

SSP: sistema silvopastoril / SSP: silvopastoral system.

\section{Resultados y discusión}

Los resultados de composición química del forraje de cada arreglo evaluado se presentan en el Cuadro 4. Para ninguna de las variables se presentó efecto significativo del nivel de sombra ni de la interacción sombra $\mathrm{x}$ arreglo ( $\mathrm{p}>0,05)$. 
Cuadro 4. Análisis bromatológico del forraje correspondiente a cada arreglo evaluado en el experimento de gramíneas solas o asociadas con arbustivas en arreglos silvopastoril. Hacienda La Candelaria, Universidad de Antioquia, Caucasia, Antioquia, Colombia. 2013.

Table 4. Bromatological analysis of the forage from each arrangement evaluated in the experiment of grasses alone or associated to shrub in silvopastoral arrangement. The Candelaria farm, University of Antioquia, Caucasia, Antioquia, Colombia. 2013.

\begin{tabular}{|c|c|c|c|c|c|c|c|}
\hline $\begin{array}{l}\text { Arreglo (gramínea } \\
\text { sola o asociada a } \\
\text { arbustiva)* }\end{array}$ & Ceniza \% & FDN\% & FDA \% & PC\% & EE\% & $\begin{array}{c}\text { ACL } \\
\text { g/100 g de } \\
\text { MS }\end{array}$ & $\begin{array}{l}\text { ACLN } \\
\text { g/100 g de } \\
\text { MS }\end{array}$ \\
\hline $\mathrm{BD}$ & 8,61 & 69,4967 & 43,3638 & $8,64 a b$ & 1,49 & $0,1845 \mathrm{~b}$ & 0,4708 \\
\hline $\mathrm{BD}+\mathrm{C}$ & 8,38 & 68,3283 & 41,6922 & $8,91 \mathrm{ab}$ & 1,63 & $0,1903 a b$ & 0,461 \\
\hline $\mathrm{BD}+\mathrm{C}+\mathrm{T}$ & 9,75 & 68,4033 & 41,6188 & $7,89 a b$ & 1,27 & $0,2428 a b$ & 0,4673 \\
\hline $\mathrm{BD}+\mathrm{T}$ & 9,13 & 68,7767 & 42,8772 & $9,14 a b$ & 1,76 & $0,2367 a b$ & 0,5152 \\
\hline $\mathrm{BM}$ & 9,49 & 67,6283 & 38,9122 & $9,88 \mathrm{a}$ & 1,92 & $0,2427 \mathrm{ab}$ & 0,6417 \\
\hline $\mathrm{BM}+\mathrm{C}$ & 9,66 & 67,0733 & 40,3022 & $9,23 a b$ & 1,88 & $0,2313 \mathrm{ab}$ & 0,5912 \\
\hline $\mathrm{BM}+\mathrm{C}+\mathrm{T}$ & 9,52 & 67,3267 & 41,0905 & $8,89 \mathrm{ab}$ & 2,17 & $0,2345 a b$ & 0,564 \\
\hline $\mathrm{BM}+\mathrm{T}$ & 9,90 & 67,9217 & 41,6155 & $9,50 \mathrm{ab}$ & 2,03 & $0,2577 \mathrm{ab}$ & 0,6158 \\
\hline BT & 8,50 & 70,1917 & 43,0388 & $6,44 \mathrm{~b}$ & 1,80 & $0,2203 a b$ & 0,4637 \\
\hline $\mathrm{BT}+\mathrm{C}$ & 9,00 & 69,9817 & 44,7872 & $7,53 \mathrm{ab}$ & 1,62 & $0,2617 a b$ & 0,5533 \\
\hline $\mathrm{BT}+\mathrm{C}+\mathrm{T}$ & 8,56 & 70,68 & 41,9488 & $6,38 \mathrm{~b}$ & 1,71 & $0,2775 \mathrm{a}$ & 0,6037 \\
\hline $\mathrm{BT}+\mathrm{T}$ & 8,82 & 69,5717 & 44,0588 & $7,61 \mathrm{ab}$ & 2,17 & $0,2808 \mathrm{a}$ & 0,5585 \\
\hline Error estándar & 0,4277 & 1,2063 & 1,1608 & 0,7437 & 0,198 & 0,033 & 0,121 \\
\hline Sombra & 0,8937 & 0,636 & 0,9944 & 0,1597 & 0,6463 & 0,9844 & 0,4379 \\
\hline Arreglo & 0,069 & 0,485 & 0,0562 & 0,0179 & 0,0549 & 0,0268 & 0,4579 \\
\hline Sombra $\mathrm{x}$ arreglo & 0,715 & 0,7098 & 0,3489 & 0,8351 & 0,2317 & 0,4082 & 0,7022 \\
\hline
\end{tabular}

* BT: Brachiaria brizantha cv toledo, BD: Brachiaria decumbens, BM: Brachiaria hibrido cv mulato II, C: Cratylia argentea, T: Tithonia diversifolia.

FDN: fibra detergente neutro; FDA: fibra detergente ácido; PC: proteína cruda; EE: extracto etéreo; ACL: ácido linoleico; ACLN: ácido linolénico / FDN: neutral detergent fiber; FDA: acid detergent fiber; PC: crude protein; EE: ether extract; ACL: linoleic acid, ACLN: linolenic acid.

El arreglo utilizado afectó significativamente $(\mathrm{p}<0,05)$ la concentración de proteína cruda $(\mathrm{PC})$. El mayor contenido de proteína se registró para la gramínea Brachiaria hibrido cv mulato II (BM) en monocultivo. BM en monocultivo solo superó significativamente en 3,44 y 3,50\% los registros de proteína observados en la gramínea $B$. brizantha cv toledo en monocultivo y en el arreglo SSP que incluyó toledo, $C$. argentea y $T$. diversifolia respectivamente. Contrario a lo esperado, el asocio de gramíneas y arbustivas en la combinación de arreglos SSP no incrementó significativamente la concentración de proteína cuando se comparó con la respectiva gramínea en monocultivo. Los arreglos SSP evaluados tampoco presentaron diferencia significativa en su concentración proteica cuando se compararon con la gramínea BM en monocultivo, excepto BT+C+T.

Los resultados obtenidos en el presente trabajo para el contenido de proteína cruda en las gramíneas solas (9,38\% B.M y 6,94\% BT) fueron inferiores a los reportados por Argel et al. (2007) bajo condiciones de suelos ácidos (pH=5,1 y 64\% de saturación de aluminio) para Brachiaria hibrido cv mulato II (11,4\% de PC); y para $B$. brizantha cv toledo $(9,1 \%$ PC). En referencia al cultivar Toledo en condiciones de monocultivo, se observó un 
valor de PC inferior a 7\%, lo cual podría limitar el funcionamiento ruminal (Minson, 1990; Leng, 1993). Estos resultados podrían estar relacionados con el alto contenido de aluminio y la baja fertilidad general del suelo en este estudio, a la pérdida de calidad bromatológica del pasto, influenciada por la edad de cosecha (cuarenta días); al respecto Lascano et al. (2002), indicaron que a partir de los 45 días de rebrote esta gramínea puede presentar valores inferiores al $8 \%$ de PC.

Con relación a la asociación de pastos con árboles leguminosos, se ha encontrado un mayor contenido de proteína en el pasto relacionado con un mayor reciclaje de nutrientes, sumado a la fijación de nitrógeno (Treydet et al., 2007). C. argentea, es una leguminosa, y T. diversifolia, que aunque no es leguminosa, se ha reportado que establecen asociaciones con hongos micorrízicos y ciertas micorrizas, que pueden ser importantes en la toma de nutrientes por la planta, como el N (Leigh et al., 2009). Sin embargo, cuando se comparó el contenido de proteína del Panicum maximum con el de un sistema silvopastoril conformado con pasto más arbustos vs el pasto en monocultivo, no se encontraron diferencias significativas, pero sí cuando se comparó con un sistema más complejo de pasto-arbustos y árboles (Barragán, 2013). Asimismo, González et al. (2012) estudiaron, bajo pastoreo a los veintiocho días de rebrote, la calidad bromatológica del B. brizantha cv toledo solo y en asocio con C. argentea, sin encontrar diferencias significativas en el contenido de proteína, con valores de 8,3 y $8,7 \%$ para el toledo asociado a $C$. argentea y en monocultivo, respectivamente. Al respecto Paciullo et al. (2011) comparando el comportamiento de $B$. decumbens sola y en SSP con árboles leguminosos (Acacia mangium, A. Angustissima y Mimosa artemisiana), informaron que los incrementos en la proteína de la gramínea estuvieron influenciados por la degradación de la materia orgánica y el reciclaje de nutrientes en suelos con sombrío, lo cual podría indicar que los resultados en la respuesta en proteína en asocios de gramíneas y arbustivas o árboles, estaría determinada por el mayor reciclaje de nutrientes, la densidad de sombra y el tipo de pasto asociado.

El contenido de FDA en las gramíneas en monocultivo y en las asociaciones gramínea-arbustiva, presentó una tendencia estadística $(\mathrm{p}=0,0562)$. Las concentraciones más bajas de FDA se registraron en la gramínea BM y todas sus combinaciones con las arbustivas, con registros que variaron entre 38,9 y 41,6\% (Cuadro 2). Los registros más altos de FDA se reportaron para la gramínea BT combinada con las arbustivas $C$. argentea y $T$. diversifolia, con valores de 44,7 y 44,05\%, respectivamente. Los resultados en FDA para B. brizantha $\mathrm{cv}$ toledo fueron consistentes a los encontrados para proteína, y reflejan la pérdida de valor nutricional a los días de corte evaluado.

Las concentraciones de ceniza y de extracto etéreo presentaron una tendencia estadística entre arreglos $(\mathrm{p}<0,1)$. En casi todos los arreglos en donde hubo combinaciones gramínea-arbustivas se observó una tendencia estadística hacia un mayor porcentaje de cenizas y de extracto etéreo, comparado con la respectiva gramínea sola. Diferentes autores han reportado que el botón de oro es una planta con unas altas concentraciones de cenizas $(13,7$ a 21,4\% de cenizas) (Rosales, 1992; Sarria et al., 2003; González et al., 2014), lo cual puede ser atribuido a que los miembros de la familia Arastaceae tienden a acumular grandes cantidades de sales inorgánicas en sus forrajes (Lezcano et al., 2012).

Al igual que en las concentraciones de cenizas, se ha informado que T. diversifolia es un forraje con una concentración de grasas superior a la registrada en una gramínea promedio (Mahecha y Rosales, 2005; Mahecha et al., 2007; García et al., 2008; Pérez et al., 2009; González et al., 2014). Para este arbusto forrajero se reportan valores entre 1,4 y $3,4 \%$ de extracto etéreo de la materia seca. Para Cratylia argentea se reportan valores de 9,4 y 3,1\% para ceniza y extracto etéreo, respectivamente. El hecho que en el presente trabajo solo se presentó una tendencia estadística, podría estar relacionado con la baja inclusión de la arbustiva en la muestra.

Los resultados obtenidos en el presente trabajo registraron efecto del arreglo SSP evaluado en la concentración de ácido linoleico $(\mathrm{p}<0,05)$. El asocio de $B$. brizantha $\mathrm{cv}$ toledo con $T$. diversifolia presentó la mayor concentración de este ácido graso $(0,28 \mathrm{~g} / 100 \mathrm{~g}$ de MS), seguida de la combinación de $B$. brizantha cv toledo con ambas arbustivas $(0,277 \mathrm{~g} / 100 \mathrm{~g}$ de MS), registrando, en ambos casos, diferencias significativas con el valor más bajo, encontrado en la gramínea $B$. decumbens en monocultivo $(0,184 \mathrm{~g} / 100 \mathrm{~g}$ de MS). Aunque no se encontraron otros 
reportes de ácidos grasos en estas especies, los resultados obtenidos resultan de interés para futuras evaluaciones sobre los efectos de estas asociaciones en la calidad de la grasa de la carne y de la leche, y con su potencial efecto en la disminución de GEI. Aumentos en la disponibilidad de ácido linoleico en el forraje sumado a la disponibilidad de taninos a nivel ruminal se han relacionado con una mayor disponibilidad de ácido transvaccénico, que es el principal precursor de ácido linoleico conjugado (ALC), ácido graso con potenciales beneficios para la salud humana (Lourenco et al., 2008). Collomb et al. (2006) reportaron cómo la diversidad de las pasturas incrementó los contenidos de ALC en la leche, comparados con los niveles encontrados en pasturas puras, asociado con la presencia de algunos metabolitos secundarios que se encuentran en las pasturas, y que se sugieren como potenciales modificadores de la biohidrogenación ruminal.

El resultado de degradación de la materia seca a las 48 h no presentó efecto significativo del arreglo $(\mathrm{p}=0,1267)$ de la sombra $(\mathrm{p}=0,6305)$, ni de la interacción de ambos factores $(\mathrm{p}=0,3418)$. Sin embargo, al realizar las comparaciones planeadas, sí se registraron efectos significativos o tendencias estadísticas (Cuadro 5).

Cuadro 5. Promedios, error estándar (EE) y valor de p (p) para la variable degradación de la materia seca a las 48 h encontrados en las diferentes comparaciones planeadas realizadas con arreglos utilizados en el experimento. Hacienda la Candelaria, Universidad de Antioquia, Caucasia, Antioquia, Colombia. 2013.

Table 5. Averages, standard error (SE) and $\mathrm{p}(\mathrm{p})$ for degradation of dry matter at $48 \mathrm{~h}$ found in the different planned comparisons made whit the arrangement used in the experiment. The Candelaria farm, University of Antioquia, Caucasia, Antioquia, Colombia. 2013.

\begin{tabular}{|c|c|c|c|c|c|}
\hline Comparación* & $\begin{array}{c}\text { Estimador de diferencia } \\
\text { entre la comparación }\end{array}$ & $\begin{array}{c}\text { Error estándar de la } \\
\text { diferencia }\end{array}$ & DF & Valor $\mathbf{t}$ & Valor $\mathrm{p}$ \\
\hline $\mathrm{BD}$ vs $\mathrm{BD}+\mathrm{C}$ & 2,0017 & 2,1957 & 33 & 0,91 & 0,3686 \\
\hline $\mathrm{BD}$ vs $\mathrm{BD}+\mathrm{C}+\mathrm{T}$ & $-0,6333$ & 2,1957 & 33 & $-0,29$ & 0,7748 \\
\hline $\mathrm{BD}$ vs $\mathrm{BD}+\mathrm{T}$ & $-0,795$ & 2,1957 & 33 & $-0,36$ & 0,7196 \\
\hline $\mathrm{BD}$ vs $\mathrm{BM}$ & $-4,4717$ & 2,1957 & 33 & 2,04 & 0,0498 \\
\hline $\mathrm{BD}$ vs $\mathrm{BT}$ & $-3,1233$ & 2,1957 & 33 & $-1,42$ & 0,1643 \\
\hline $\mathrm{BM}$ vs $\mathrm{BT}$ & 7,595 & 2,1957 & 33 & 3,46 & 0,0015 \\
\hline $\mathrm{BM}$ vs $\mathrm{BM}+\mathrm{C}$ & 1,9217 & 2,1957 & 33 & 0,88 & 0,3878 \\
\hline $\mathrm{BM}$ vs $\mathrm{BM}+\mathrm{C}+\mathrm{T}$ & 3,9583 & 2,1957 & 33 & 1,8 & 0,0806 \\
\hline $\mathrm{BM}$ vs $\mathrm{BM}+\mathrm{T}$ & 2,4383 & 2,1957 & 33 & 1,11 & 0,2748 \\
\hline $\mathrm{BT}$ vs $\mathrm{BT}+\mathrm{C}$ & $-4,5183$ & 2,1957 & 33 & $-2,06$ & 0,0476 \\
\hline $\mathrm{BT}$ vs $\mathrm{BT}+\mathrm{C}+\mathrm{T}$ & $-2,49$ & 2,1957 & 33 & $-1,13$ & 0,265 \\
\hline $\mathrm{BT}$ vs $\mathrm{BT}+\mathrm{T}$ & $-3,9667$ & 2,1957 & 33 & $-1,81$ & 0,08 \\
\hline $\mathrm{BD} \mathrm{BM} \mathrm{BT}$ vs $\mathrm{BD}+\mathrm{C} \mathrm{BM}+\mathrm{C} \mathrm{BT}+\mathrm{C}$ & $-0,595$ & 3,8031 & 33 & $-0,16$ & 0,8766 \\
\hline $\begin{array}{l}\mathrm{BD} \quad \mathrm{BM} \quad \mathrm{BT} \text { vs } \mathrm{BD}+\mathrm{C}+\mathrm{T} \quad \mathrm{BM}+\mathrm{C}+\mathrm{T} \\
\mathrm{BT}+\mathrm{C}+\mathrm{T}\end{array}$ & $-0,595$ & 3,8031 & 33 & $-0,16$ & 0,8766 \\
\hline $\begin{array}{l}\mathrm{BD} B M \quad \mathrm{BT} \text { vs } \mathrm{BD}+\mathrm{C}+\mathrm{T} \quad \mathrm{BM}+\mathrm{C}+\mathrm{T} \\
\mathrm{BT}+\mathrm{C}+\mathrm{T}\end{array}$ & 0,835 & 3,8031 & 33 & 0,22 & 0,8276 \\
\hline BD BM BT vs BD+T BM+T BT+T & $-2,3233$ & 3,8031 & 33 & $-0,61$ & 0,5454 \\
\hline $\mathrm{BD}$ vs $\mathrm{BD}+\mathrm{C} \mathrm{BM}+\mathrm{C}+\mathrm{T} \mathrm{BD}+\mathrm{T}$ & 0,1901 & 1,7928 & 33 & 0,11 & 0,9162 \\
\hline $\mathrm{BM}$ vs $\mathrm{BM}+\mathrm{C} \mathrm{BM}+\mathrm{T}+\mathrm{C} \mathrm{BM}+\mathrm{T}$ & 2,7724 & 1,7928 & 33 & 1,55 & 0,1315 \\
\hline $\mathrm{BT}$ vs $\mathrm{BT}+\mathrm{C} \mathrm{BT}+\mathrm{C}+\mathrm{T} \mathrm{BT}+\mathrm{T}$ & $-3,6586$ & 1,7928 & 33 & $-2,04$ & 0,0493 \\
\hline
\end{tabular}

* BT: Brachiaria brizantha cv toledo, BD: Brachiaria decumbens, BM: Brachiaria hibrido cv mulato II, C: Cratylia argentea, T: Tithonia diversifolia. 
La comparación planeada presentó efecto significativo $(\mathrm{p}<0,05)$ entre la degradabilidad a las $48 \mathrm{~h}$ de la gramínea B. hibrido cv mulato II (BM), comparada con las otras dos Brachiarias utilizadas en el estudio. No se observó diferencia significativa $(\mathrm{p}>0,05)$ entre la degradabilidad de la MS a las $48 \mathrm{~h}$ entre BD y BT. Estos resultados sugieren mejor calidad nutricional en la gramínea BM, con un valor de degradabilidad a las 48 h que alcanzó 56,6\% de la materia seca (MS); seguido de la gramínea BD $(52,1 \%)$, y por último, BT $(48,9 \%)$. Los resultados obtenidos pueden ser atribuidos a las características bromatológicas observadas en cada pastura, ya que la edad de cosecha utilizada (cuarenta días) pudo influir en la calidad del forraje. Quintino et al. (2013) encontraron que la edad de la planta afectó significativamente la digestibilidad in vitro de B. brizantha. Está bien documentado el efecto negativo de aportes deficientes de nitrógeno en la dinámica ruminal (Minson, 1990), así como también, la restricción que imponen altas concentraciones de fibra en la digestibilidad de la dieta (Van Soest, 1994).

Pese a observarse menor calidad nutricional en términos de degradación de la MS para la gramínea BT, los resultados de las pruebas planedas de la gramínea sola y acompañada de las arbustivas T. diversifolia o C. argentea, sugieren que el asocio mejoró significativamente $(\mathrm{p}<0,05)$ la degradabilidad de la MS. Los resultados obtenidos indicaron que el asocio de la gramínea BT con la arbustiva $C$. argentea, incrementó en 4,51\% la degradabilidad de la MS en relación a monocultivo; y demostró una tendencia estadística $(\mathrm{p}=0,08)$ al estar acompaña de $T$. diversifolia, alcanzando una degradación de $52,9 \%$ de la MS.

Los resultados obtenidos concuerdan con los reportados por Morales et al. (2013), quienes encontraron que la calidad nutricional de las pasturas incrementó cuando se asoció con Lotus uliginosus. Sin embargo, fueron opuestos a los de Balseca et al. (2015), quienes encontraron que la asociación de leguminosas (C. pubescens y C. cajan) con Brachiarias no afectó la calidad nutricional de las raciones. Los resultados del presente estudio indicaron que la calidad nutricional de BT fue mayor cuando se asoció con las arbustivas que cuando estuvo en monocultivo. En otra investigación $B$. brizantha respondió significativamente a la asociación con $T$. diversifolia comparada con el monocultivo, incrementando significativamente la proporción de hojas, disminuyendo la proporción de tallos, y con una tendencia a una mayor producción de materia seca sin afectar su altura (Mahecha et al., 2015). En la misma investigación, también se encontró respuesta positiva en esas variables para BD al estar asociada con las arbustivas; sin embargo, en el presente trabajo no hubo respuesta positiva significativa de la asociación, para la degradabilidad de la MS del forraje a $48 \mathrm{~h}$ en esta gramínea.

El análisis de los parámetros obtenidos de la cinética de degradación (Cuadro 6), de acuerdo con lo descrito por Orskov y McDonald (1979), indicó un efecto significativo de la interacción sombra x arreglo $(\mathrm{p}<0,05)$ en el parámetro a (intercepto con el eje $\mathrm{Y}$ en el tiempo cero), y una tendencia estadística $(\mathrm{p}=0,0671)$ de la interacción sombra $\mathrm{x}$ arreglo en el parámetro c (tasa constante de la función b).

La fracción a en la combinación $\mathrm{BT}+\mathrm{C}+\mathrm{T}$ bajo la condición sin sombra, fue menor, y presentó diferencia significativa $(\mathrm{p}<0,05)$ y una tendencia estadística $(\mathrm{p}=0,0785)$, con la fracción a de la misma combinación bajo la condición de $60 \%$ y $30 \%$ de retención de luz, respectivamente. Estos resultados indicaron que al incrementar la cantidad de sombra, hubo una disminución lineal de la materia seca rápidamente degradable en rumen, asociada a la combinación BT+C+T. Sin embargo, pese a no registrarse diferencias significativas en los parámetros b y c, la simulación de la degradación potenciada hasta las 72 h (Figura 1), indicó que bajo la condición de retención del 30\% de la luz, las combinaciones BM+C y BD+T obtienen la mayor tasa de degradación con valores que alcanzan el 78,6 y 76,9\% de la MS. Asimismo, se observó, que al disminuir el 30\% de luz, las gramíneas en monocultivo presentaron menor degradación potencial, que al estar asociadas a arbustivas.

La interacción entre el arreglo utilizado y el nivel de sombra indicó que algunos asocios responden de manera diferente a la disminución en la incidencia vertical de luz. En las gramíneas del género Brachiaria, las cuales han sido descritas como medianamente tolerantes a ambientes bajo sombra (Wong, 1991), han sido reportados cambios en el porcentaje de materia seca (Gobbi, 2007), modificaciones en la altura de la planta y cambios en su área foliar específica (Martuscello et al., 2009), como respuesta a alteraciones en la incidencia de luz. Estas alteraciones 
Cuadro 6. Parámetros de degradabilidad del forraje de cada arreglo evaluado en el experimento de gramíneas solas o asociadas a arbustivas en arreglos silvopastoriles, a diferentes niveles de sombra. Hacienda La Candelaria, Universidad de Antioquia, Caucasia, Antioquia, Colombia. 2013.

Table 6. Degradability parameters of the forage from each arrangement evaluated in the experiment of grasses alone or associated to shrubs in silvopastoral arragements, in different shade levels. The Candelaria farm, University of Antioquia, Caucasia, Antioquia, Colombia. 2013.

\begin{tabular}{lccccccccc}
\hline $\begin{array}{l}\text { Arreglo (asociación } \\
\text { gramínea sola o }\end{array}$ & \multicolumn{3}{c}{$\mathbf{A}$} & \multicolumn{3}{c}{$\mathbf{B}$} & \multicolumn{3}{c}{$\mathbf{C}$} \\
\cline { 2 - 10 } asociada a arbustiva)* & Sombra & Sombra & Sombra & Sombra & Sombra & Sombra & Sombra & Sombra & Sombra \\
BD & $\mathbf{0}$ & $\mathbf{3 0}$ & $\mathbf{6 0}$ & $\mathbf{0}$ & $\mathbf{3 0}$ & $\mathbf{6 0}$ & $\mathbf{0}$ & $\mathbf{3 0}$ & $\mathbf{6 0}$ \\
BD+C & 1,170 & 1,025 & 1,690 & 62,23 & 47,35 & 59,8 & 0,04 & 0,07 & 0,045 \\
BD+C+T & 0,905 & 2,205 & 1,135 & 47,75 & 50,665 & 58,21 & 0,075 & 0,04 & 0,055 \\
BD+T & 1,110 & 1,795 & 1,825 & 55,835 & 54,45 & 56,2 & 0,045 & 0,055 & 0,055 \\
BM & 1,420 & 2,510 & 1,710 & 56,09 & 83,055 & 55,43 & 0,05 & 0,035 & 0,055 \\
BM+C & 2,165 & 2,445 & 1,215 & 66,325 & 58,64 & 57,405 & 0,04 & 0,045 & 0,065 \\
BM+C+T & 1,220 & 2,520 & 0,630 & 56,13 & 81,135 & 54,475 & 0,06 & 0,035 & 0,08 \\
BM+T & 2,355 & 2,965 & 1,975 & 59,66 & 63,76 & 54,625 & 0,035 & 0,035 & 0,065 \\
BT & 1,370 & 2,040 & 0,595 & 60,375 & 55,755 & 54,68 & 0,05 & 0,045 & 0,07 \\
BT+C & 0,385 & 1,045 & 1,430 & 46,935 & 49,395 & 66,08 & 0,075 & 0,06 & 0,04 \\
BT+C+T & 2,070 & 1,475 & 1,330 & 77,015 & 53,12 & 56,915 & 0,03 & 0,05 & 0,05 \\
BT+T & 5,365 & 1,145 & 0,600 & 94,29 & 52,43 & 52,8 & 0,015 & 0,06 & 0,07 \\
\hline Error estándar & 1,310 & 1,900 & 0,885 & 61,115 & 55,34 & 55,84 & 0,035 & 0,045 & 0,06 \\
Sombra & 0,9554 & & & 9,765 & & & 0,1299 & \\
Arreglo & 0,7079 & & & 0,4402 & & & 0,4035 & \\
Sombra x arreglo & 0,1131 & & & 0,7818 & & & 0,8291 &
\end{tabular}

* BT: Brachiaria brizantha cv toledo, BD: Brachiaria decumbens, BM: Brachiaria hibrido cv mulato II, C: Cratylia argentea, T: Tithonia diversifolia.

morfológicas, son correspondientes con cambios bromatológicos que pueden alterar la dinámica de degradación ruminal de compuestos fibrosos.

Contrario a lo esperado con relación a la emisión de metano producto de la fermentación in vitro, no se observó efecto significativo de los factores evaluados ( $\mathrm{p}>0,05$ ), con valores que variaron entre 26,2 y $38,1 \mathrm{ml} \mathrm{de} \mathrm{CH}_{4} / \mathrm{g}$ de MS incubada para el forraje de los diferentes arreglos evaluados. Varios autores han afirmado que la inclusión de especies arbustivas en la dieta de rumiantes puede constituirse en una oportunidad para disminuir las emisiones de metano entérico (Kamra et al., 2006; Lascano y Cárdenas, 2010; Mirzaei-Aghsaghali y Maheri-Sis, 2011). En ensayos in vitro, se demostró que la inclusión de T. diversifolia en un 10 y $20 \%$ de la materia seca, logró disminuir en más del 50\% la población de metanógenos en el fluido ruminal (Galindo et al., 2011). Se demostró además, que por lo menos con la inclusión de $20 \%$ de $T$. diversifolia se logró reducir la población de protozooarios, lo cual resulta de mucha importancia en la disminución de metano entérico, dado que hay una relación directa entre bacterias metanógenas y población de protozoarios (Galindo et al., 2008; Delgado et al., 2012; Galindo et al., 2012). En el caso de $C$. argentea, Meale et al. (2012) para condiciones in vitro y Hess et al. (2006) para condiciones in vivo (usando ovejas), demostraron que la inclusión de esta leguminosa baja en taninos, logró disminuir la emisión de gases de efecto invernadero hasta en un 13\%, comparado con dietas con base en gramíneas. De igual forma, Mayorga et al. (2014), empleando la técnica del poli-túnel, evidenciaron que la inclusión del 30\% de Guazuma ulmifolia en la dieta basal de novillos en crecimiento, disminuyó en 13,1\% la emisión de metano, comparados con 

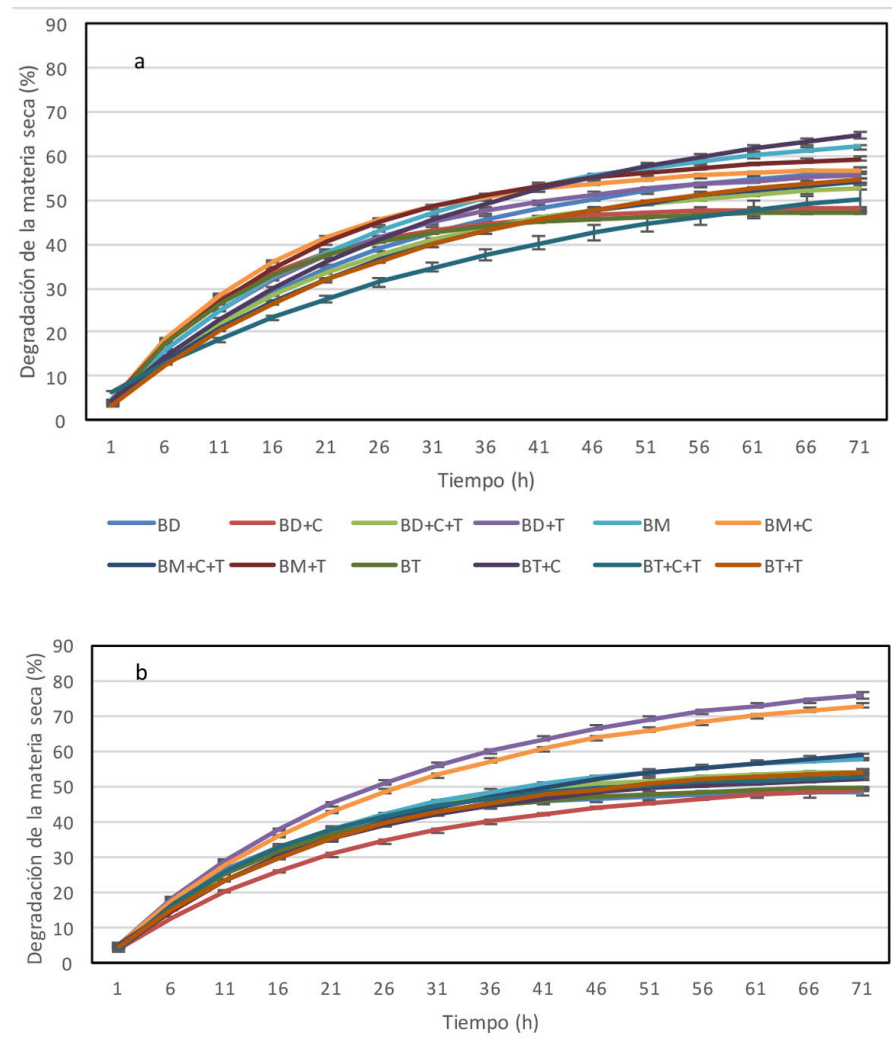

$\longrightarrow \mathrm{BD}-\mathrm{BD}+\mathrm{C} \longrightarrow \mathrm{BD}+\mathrm{C}+\mathrm{T} \longrightarrow \mathrm{BD}+\mathrm{T} \longrightarrow \mathrm{BM}=\mathrm{BM}+\mathrm{C}$

$\longrightarrow \mathrm{BM}+\mathrm{C}+\mathrm{T} \longrightarrow \mathrm{BM}+\mathrm{T} \longrightarrow \mathrm{BT} \longrightarrow \mathrm{BT}+\mathrm{C} \longrightarrow \mathrm{BT}+\mathrm{C}+\mathrm{T} \longrightarrow \mathrm{BT}+\mathrm{T}$
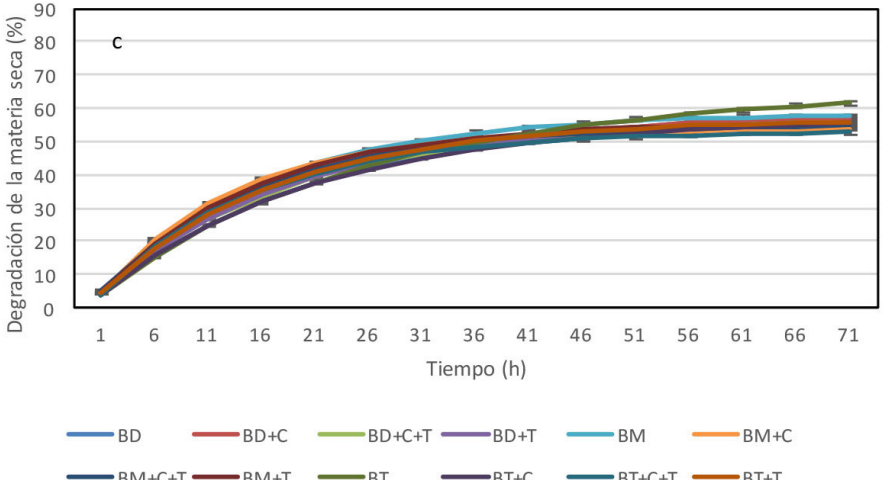

Figura 1. Degradación potencial de la materia seca para el forraje de los diferentes arreglos evaluados en el experimento de gramíneas solas o en asociación con arbustivas en arreglos silvopastoriles. Bajo condición sin sombra (a), con restricción del 30\% de luz (b) y con restricción del $60 \%$ de luz (c). Hacienda La Candelaria, Universidad de Antioquia, Caucasia, Antioquia, Colombia. 2013.

Figure 1. Potential degradation of dry matter of forage from different arrangement evaluated in the experiment of grasses alone or associated to shrubs in silvopastoral arragements. On condition unshaded (a), restricted to $30 \%$ of light (b) and $60 \%$ restriction of light (c). The Candelaria farm, University of Antioquia, Caucasia, Antioquia, Colombia. 2013.

BT: Brachiaria brizantha cv toledo, BD: Brachiaria decumbens, BM: Brachiaria hibrido cv mulato II, C: Cratylia argentea, T: Tithonia diversifolia. 
dietas $100 \%$ P. maximum. Por otro lado, se tenía la premisa que el cambio en la calidad nutricional del forraje, incluido su contenido de ácidos grasos insaturados, influiría en la producción in vitro de metano; sin embargo, los resultados encontrados parecieran indicar que los cambios estructurales y nutricionales encontrados en las asociaciones pasto-arbustiva comparados con el pasto solo, no habrían sido suficientes para impactar las poblaciones de agentes productores de metano, posiblemente debido a la baja inclusión de las arbustivas en las muestras evaluadas. Sería importante considerar una mayor inclusión de arbustivas en las muestras a evaluar en futuras investigaciones, de forma que representen un mayor porcentaje de las arbustivas en los arreglos silvopastoriles que se hagan en campo.

\section{Literatura citada}

AOAC (Association of Official Agricultural Chemists). 1999. AOAC: Official methods of analysis. $16^{\text {th }}$ ed (5 $5^{\text {th }}$ rev.). AOAC International, Gaithersburg, MD, USA.

Apráez, J.E., J.M. Delgado, y J.P. Narváez. 2012. Composición nutricional, degradación in vitro y potencial de producción de gas de herbáceas, arbóreas y arbustivas encontradas en el trópico alto de Nariño. Liv. Res. Rural Dev. 24(3). http://www. lrrd.org/lrrd24/3/apra24044.htm

Argel, P., J. Miles, J. Guiot, H. Cuadrado, y C.E. Lascano. 2007. Cultivar Mulato II (Brachiaria hibrido CIAT 36087): gramínea de alta calidad y producción forrajera, resistente a salivazo y adaptada a suelos tropicales ácidos bien drenados. CIAT, COL.

Balseca, D.G., E.G. Cienfuegos, H.B. López, H.P. Guevara, and J.C. Martínez. 2015. Nutritional value of Brachiarias and forage legumes in the humid tropics of Ecuador. Cienc. Inv. Agr. 42:57-63.

Barragán, W.A. 2013. Sistemas silvopastoriles para mejorar la producción de leche y disminuir el estrés calórico en la región Caribe colombiana. Universidad de Antioquia, COL.

Carmona, J.C., D.M Bolivar, y L.A. Giraldo. 2005. El gas metano en la producción ganadera y alternativas para medir sus emisiones y aminorar su impacto a nivel ambiental y productivo. Rev. Colom. Cienc. Pecu. 18:49-63.

Collomb, M., A. Schmid, R. Sieber, D. Wechsler, and E.L. Ryhanen. 2006. Conjugated linoleic acid in milk fat: Variation and physiological effects. J. Dairy Sci. 16:1347-1361.

Cote, M., M. Piedad, J. Gonzáles, y A. Cardona. 2010. El cambio climático en Colombia y en el sistema de las Naciones Unidas. PNUD, Bogotá, COL.

Delgado, D., J. Galindo, R. González, N. González, I. Scull, L. Dihigo, J. Cairo, A. Aldama, and O. Moreira. 2012. Feeding of tropical trees and shrub foliages as a strategy to reduce ruminal methanogenesis: studies conducted in Cuba. Trop. Anim. Prod. 44:1097-1104.

Galindo, J., N. González, D. Delgado, A. Sosa, Y. Marrero, R. González, A. Aldana, y O. Moreira. 2008. Efecto modulador de Leucaena leucocephala sobre la microbiota ruminal. Zootec. Trop. 26:249-252.

Galindo, J., N. González, I. Scull, Y. Marrero, A. Sosa, A. Aldana, O. Moreira, D. Delgado, T. Ruiz, G. Febles,V. Torres, O. La O, L. Sarduy, A. Noda, y O. Achang. 2012. Efecto de Samanea saman (Jacq.) Merr., Albizia lebbeck (L.) Benth y Tithonia diversifolia (Hemsl.) Gray (material vegetal 23) en la población de metanógenos y en la ecología microbiana ruminal. Rev. Cubana Cienc. Agríc. 46:273-278.

Galindo, J., N. González, A. Sosa, T. Ruíz, V. Torres, A. Aldana, y A. Noda. 2011. Efecto de Tithonia diversifolia (Hemsl.) Gray (botón de oro) en la población de protozoos y metanógenos ruminales en condiciones in vitro. Rev. Cubana Cienc. Agríc. 45:33-37. 
García, D.E., M.G. Medina, L.J. Cova, A. Torres, M. Soca, P. Pizzani, y C.E. Domínguez. 2008. Preferencia de vacunos por el follaje de doce especies con potencial para sistemas agrosilvopastoriles en el estado Trujillo, Venezuela. Pastos y Forrajes $31: 255-2270$.

Gobbi, K. 2007. Caracteristicas morfoanatomicas, nutricionais e productividade de forrageiras tropicais submetidas ao sombramiento. Tese Dr., Universidade Federal de Viçosa, BRA.

González, A., B. De-la-Mora, M. Alonso, E. Gallegos, E. Zavaleta, and J. Rodríguez. 2012. Effect of grazing Cratylia argentea associated with Brachiaria brizantha-Toledo on quality pasture and weight gain in holstein x zebu heifers. Trop. Subtrop. Agroecosyst. 15:S1-S11.

González-Castillo, J.C., C.M. Hahn von-Hessberg, y W. Narváez-Solarte. 2014. Características botánicas de Tithonia diversifolia (asterales: asteraceae) y su uso en la alimentación animal. Bol. Cient. Mus. Hist. Nat. 18(2):45-58.

Grainger, C., and K.A. Beauchemin. 2011. Can enteric methane emissions from ruminants be lowered without lowering their production? Anim. Feed Sci. Tencnol. 166-167:308-320.

Hess, H.D., R.A. Beuret, M. Lotscher, I.K. Hindrichsen, A. Machmuller, J.E. Carulla, C.E. Lascano, and M. Kreuzer. 2004. Ruminal fermentation, methanogenesis and nitrogen utilization of sheep receiving tropical grass hay-concentrate diets offered with Sapindus saponaria fruits and Cratylia argentea foliage. Anim. Sci. 79:177-189.

Hess, H.D., T.T. Tiemann, F. Noto, J.E. Carulla, and M. Kreuzer. 2006. Strategic use of tannins as means to limit methane emission from ruminant livestock. Int. Cong. Series 1293:164-167.

Hristov, A.N., J. Oh, J.L. Firkins, J. Dijkstra, E. Kebreab, G. Waghorn, and P.J. Gerber. 2013. Special topics mitigation of methane and nitrous oxide emissions from animal operations: I. A review of enteric methane mitigation options. J. Anim. Sci. 91:5045-5069.

Jalc, D., M. Certik, K. Kundrikova, and P. Namestkova. 2007. Effect of unsaturated C-18 fatty acids (oleic, linoleic and alphalinolenic acid) on ruminal fermentation and production of fatty acid isomers in an artificial rumen. Vet. Med. 52:87-94.

Johnson, K.A., and D.E. Johnson. 1995. Methane emissions from cattle. J. Anim Sci. 73:2483-2492.

Kamra, D.N., N. Agarwal, and L.C. Chaudhary. 2006. Inhibition of ruminal methanogenesis by tropical plants containing secondary compounds. Int. Cong. Series 1293:156-163.

Lascano, C.E., and E. Cárdenas. 2010. Alternatives for methane emission mitigation in livestock systems. R. Bras. Zootec. 39:175-182.

Lascano, C.E., R. Pérez, B. Plazas, H. Camilo, J. Medrano, M. Argel, y J. Pedro. 2002. Pasto Toledo (Brachiaria brizantha CIAT 26110): gramínea de crecimiento vigoroso para intensificar la ganadería colombiana. Corporación Colombiana de Investigación Agropecuaria y CIAT, Cali, COL.

Leigh, J., A. Hodge, and A.H. Fitter. 2009. Arbuscular mycorrhizal fungi can tranfer substantial amounts of nitrogen to their host plant from organic material. New Phytol. 181:199-207.

Leng, R.A. 1993. Quantitative ruminant nutrition a green science. Crop Pasture Sci. 44:363-380.

León, J., M. Pabón, y J.C. Carulla. 2011. Relación entre las características de la pastura y el contenido de ácido linoleico conjugado (ALC) en la leche. Rev. Colom. Cienc. Pecu. 24:63-73.

Lezcano, Y., M. Soca, F. Ojeda, E. Roque, D. Fontes, I.L. Montejo, y N. Cubillas. 2012. Caracterización bromatológica de Tithonia diversifolia (Hems1.) A. Gray en dos etapas de su ciclo fisiológico. Pastos y Forrajes 35:275-282.

Lopez, S., and C.J. Newbold. 2007. Analysis of methane. En: H.P.S. Makkar, and P.E. Vercoe, editors, Measuring methane production from ruminants. Springer, Dordrecht, HOL. p. 1-13. 
Lourenco, M.G., B. Van-Ranst, S. Vlaeminck, S. De-Smet, and V. Fievez. 2008. Influence of different dietary forages on the fatty acid composition of rumen digesta as well as ruminant meat and milk. Anim. Feed Sci. Technol. 145:418-437.

Mahecha, L., J. Angulo, y W. Barragán. 2015. Efecto de la sombra en cambios estructurales de Brachiarias asociadas a T. diversifolia y/o C. argentea. En: P. Peri, editor, $3^{\circ}$ Congreso Nacional de Sistemas Silvopastoriles: VII Congreso Internacional Sistemas Agroforestales. Ediciones INTA, COL. p. 294-298.

Mahecha, L., J.P. Escobar, J.F. Suárez, y L.F. Restrepo. 2007. Tithonia diversifolia (hemsl.) Gray (botón de oro) como suplemento forrajero de vacas F1 (Holstein por Cebú). Liv. Res. Rural Dev. 19(2). http://www.lrrd.org/lrrd19/2/mahe19016.htm

Mahecha, L., D. Giraldo, J.F. Arroyave, y L. Restrepo. 2004. Evaluación del silvopastoreo como alternativa para el manejo del destete precoz en terneros Cebú. Liv. Res. Rural Dev. 16. http://www.lrrd.org/lrrd16/5/mahe16030.htm

Mahecha, L., y M. Rosales. 2005. Valor nutricional del follaje de botón de oro Tithonia diversifolia (Hemsl.) Gray, en la producción animal en el trópico. Liv. Res. Rural Dev. 17(9). http://www.lrrd.org/lrrd17/9/mahe17100.htm

Mc-Dougall, E.I. 1948. The composition and output of sheep's saliva. Biochem. J. 43:99-109.

Meale, S.J., A.V. Chaves, J. Baah, and T.A. McAllister. 2012. Methane production of different forages in vitro ruminal fermentation. AJAS 25:86-91.

Martin, C., D.P. Morgavi, M. Doreau, et J.P. Jouany. 2006. Comment réduire la production de méthane chez les ruminants? Fourrages 187:283-300.

Martucello, J., L. Jank, M. Neto, V. Laura, e D. Cunha. 2009. Produção de gramíneas do gênero Brachiaria sob níveis de sombreamento. R. Bras. Zootec. 38:1183-1190.

Mayorga, O., E. Angarita, R. Zambrano, J. Cardozo, y S. Ospina. 2014. Emisión de metano entérico en novillos cebú con y sin la inclusión de dietas de Guazuma ulmifolia sobre dietas de Panicum maximum en el Caribe Seco Colombiano. En: M. Alfaro et al., editores, Primera conferencia de gases de efecto invernadero en sistemas agropecuarios de Latinoamérica (GALA). Serie de Actas N 54. INIA, Osorno, CHI. p. 25-31.

Menke, K.H., and H. Steingass. 1988. Estimation of the energetic feed value obtained from chemical analysis and in vitro gas production using rumen fluid. Anim. Res. Dev. 28:7-55.

Minson, D.J. 1990. Forage in ruminant nutrition. Academic Press, San Diego, CA, USA.

Mirzaei-Aghsaghali, A., and N. Maheri-Sis. 2011. Factors affecting mitigation of methane emission from ruminants I: Feeding strategies. AJAVA 6:888-908. doi:10.14269/2318-1265/jabb.v4n1p22-31

Morales, A., J. León, E. Cárdenas, G. Afanador, y J. Carulla. 2013. Calidad de la leche, digestibilidad in vitro de la materia seca y producción en vacas alimentadas con gramíneas solas o asociadas con Lotus uliginosus. Rev. Fac. Med. Vet. Zootec. 60:32-48

Orskov, E.R., and I. McDonald. 1979. The estimation of protein degradability in the rumen from incubation measurements weighted according to rate of passage. J. Agric. Sci. 92:499-503.

Paciullo, S.C., R.T. de-Castro, C.A. de Miranda-Gomide, R.M. Maurício, F.Á. Pires, M.D. Müller, and D.F. Xavier. 2011. Performance of dairy heifers in a silvopastoral system. Liv. Sci. 141:166-172.

Pérez, A., I. Montejo, J.M. Iglesias, O. López, G.J. Martín, D.E. García, y A. Hernández. 2009. Tithonia diversifolia (Hemsl.) A. Gray. Pastos y Forrajes 32:1-15.

Pinares-Patiño, C. 2014. Mitigación de las emisiones de metano entérico de sistemas ganaderos al pastoreo. En: M. Alfaro et al., editores, Primera conferencia de gases de efecto invernadero en sistemas agropecuarios de Latinoamerica (GALA). Serie de Actas $\mathrm{N}^{\circ}$ 54. INIA, Osorno, CHI. p. 25-31. 
Posada, S.L., R. Noguera, y D. Bolívar. 2006. Relación entre presión y volumen para la implementación de la técnica in vitro de producción de gases. Rev. Col. Cienc. Pecu. 19:407-414.

Pulido, I., R. Mandius, T. Rivero, y O. Duarte, 2002. Atlas de los sistemas de producción bovina. Módulo región Caribe. Plan de modernización tecnológica de la ganadería bovina colombiana. Corpoica, Bogotá, COL.

Quintino, A.C., J.G. de-Abreu, R.G. de-Almeida, M.C.M. Macedo, L.S. Cabral, and R.L. Galati. 2013. Production and nutritive value of piatã grass and hybrid sorghum at different cutting ages. Acta Sci. Anim. Sci. 35:243-249.

Rosales, M. 1992. Nutritional value of Colombian fooder trees. Internal report. CIPAV and NRI, GBR.

Sarria, P. 2003. Forrajes arbóreos en la alimentación de monogástricos. ftp://193.43.36.93/docrep/fao/005/y4435s/y4435s06.pdf (consultado 20 jun. 2016).

Steinfeld, H., P. Gerber, T. Wassenaar, V. Castel, M. Rosales, and C. De Haan. 2006. Livestock's long shadow: environmental issues and options. FAO, Rome, ITA.

Treydet, A., I. Heitkonig, H. Prins, and F. Ludwig. 2007. Trees improve grass quality for herbivores in African Savannas. Perspect. Plant Ecol. Evol. Syst. 8:197-205.

Theodorou, M.K., B.A. Williams, M.S. Dhanoa, A.B. McAllan, and J. France. 1994. A simple gas production method using a pressure transducer to determine the fermentation kinetics of ruminant feeds. Anim. Feed Sci. Technol. 48:185-197.

Van Soest, P.J., J.B. Robertson, and B.A. Lewis. 1991. Methods for dietary fiber, neutral-detergent fiber and nonstarch polysaccharides in relation to animal nutrition. J. Dairy Sci. 74:3583-3597.

Van-Soest, P.J. 1994. Nutritional ecology of the ruminant. Cornell University Press, NY, USA.

Wina, E., S. Muetzel, and K. Becker. 2005. The impact of saponins or saponin-containing plant materials on ruminant production A Review. J. Agric. Food Chem. 53:8093-8105.

Wong, C.C. 1991. Shade tolerance of tropical forages: A review. In: H.M. Shelton, and W.W. Stür, editors, Forages for plantation crops. No. 32. ACIAR Proceedings. INA, AUS. p. 64-69. 